\title{
EL COMERCIO DE LEVANTE DURANTE EL VALIMIENTO DEL CONDE DUQUE DE OLIVARES (1622-1643)
}

\author{
Vicente MONTOJO MONTOJO \\ Universidad de Murcia
}

\section{Resumen}

El comercio de Alicante, entendido en su acepción de grupo mercantil, merecía un análisis pormenorizado. Teniendo en cuenta la escasez de fuentes alicantinas (casi inexistentes las municipales y notariales), se ha intentado realizar una aproximación a través de las castellanas (los protocolos notariales de Cartagena, Murcia y Yecla), que reflejan la importancia de este grupo mercantil. Un colectivo que estaba formado sobre todo por personas de origen extranjero, destacó por su originalidad en varios sentidos: por una parte, el ennoblecimiento de sus miembros, un proceso muy activo en el reinado de Felipe IV, aunque con una tradición anterior, que caracterizaba a los originarios de Italia, tales como genoveses y milaneses; por otra, era receptor de elementos diferentes, sobre todo ingleses católicos, bien relacionados con los flamencos en general, que además de tener un gran protagonismo en la actividad mercantil también consiguieron ennoblecer en Alicante (Basset, Blundel-Wirrall, Paulin), aunque a veces en un periodo posterior. Se puede abundar asimismo en el carácter estratégico de los negocios del comercio de Alicante, como los abastecimientos de algunos productos alimenticios (pescado) y especias (pimienta), o el suministro de productos bélicos (azufre, pólvora); de aquí la vigilancia que recayó sobre él, pues el gobierno del conde duque de Olivares se tuvo que enfrentar a este grupo mercantil, puesto que rompía con su actitud de cierre del mercado español a estados que no fuesen amigos y las numerosas guerras en que se metió aislaron a España.

Palabras claves: Burguesía mercantil, Comercio, Edad Moderna.

\section{Summary}

The comerce of Alicante, as understood in the context of its trading group, is worth a detailed analisis. Taking into account the scarcity of reference sources in Alicante (municipal and notarial sources are almost non-existent), an approach has been attempted through the sources in Castille (the notarial protocols of Cartagena, Murcia and Yecla), which reflect the importance of this mercantile group. A community which was formed by persons of foreign origin highlights its differences in various ways: on one hand, the 
ennoblement of its members, a process very common in the reign of Philip IV, although this had a previous tradition which applied to those of Italian origin, such as Genovese and Milanese; on the other hand were were host to differents nacionalities, especially English Catholics, who in general had good connections with the Flemish, who as well as being very active in mercantile activity, also managed in Alicante to achieve noble titles (Basset, Blundel-Wirrel, Paulin), although sometimes in a previous period. Similarly the strategic character of the commercial activities in Alicante can be widely elaborated, such as the supply of some food products (fish), and spices (pepper), or the supply war products (sulphur, gunpowder); hence the vigilance which this was subject to, as the government of Olivares had to confront the mercantile group, since it was against his attitude of closing the Spanish market to belligerent unfriendly states, and the numerous wars in which it was involved isolated Spain.

Key words: trading group, Commerce, Modern Age.

Al inicio del reinado de Felipe IV, en especial del valimiento del conde duque de Olivares, una de las muchas juntas de las que pretendió servirse para gobernar fue la de comercio (1623). Olivares hubo de observar con sorpresa que el tráfico mercantil de las especias en los puertos de Levante estaba en manos de ingleses y que los alicantinos se negaban a asumir su riesgo ${ }^{1}$. Por ello, con la Junta de Comercio, pretendió revitalizar el comercio, sobre todo el de Levante, mediante la formación de una compañía de tipo holandés, con el fin de evitar el predominio de los holandeses e ingleses en el transporte. Se proyectó crear dos cámaras, una en Barcelona y otra en Cartagena, para lo que se mantuvo conversaciones con autoridades catalanas, que al final no dieron fruto ${ }^{2}$, aunque con el paso de algunos años sí se consiguió que comerciantes de Cartagena formaran una compañía de navegación, la Flota del Mar Mediterráneo (1630), para la defensa del tráfico hacia Italia ${ }^{3}$. En ella se advierte también presencia alicantina, pues comerciantes de esta ciudad estaban asociados o emparentados con los de Cartagena. Posteriormente fue la guerra con Francia (1635-1659) la principal causa de problemas, como las incursiones de una escuadra francesa en el puerto de Alicante (1644)

El comercio de Alicante, que había experimentado la prosperidad en el reinado de Felipe III, sobre todo tras las paces con Inglaterra (1604) y Holanda (1609), sufrió un rápido declive al inicio del reinado de Felipe IV, precisamente con el estallido de las guerras de Holanda (1621) $)^{5}$ Inglaterra (1625).

1. J. CASEY, El Reino de Valencia en el siglo XVII, Madrid, 1983, p. 82.

2. P. MOLAS RiBAlTA, «Instituciones y comercio en la España de Olivares», en Studia Histórica, Historia Moderna, 5 (1987), 91-98.

3. V. Montojo Montojo, El Siglo de Oro en Cartagena (1480-1640): Sociedad y economía en una ciudad portuaria del Sureste español y su comarca, Murcia, 1993, p. 290-291.

4. A. Alberola Romá, Catalogación de los protocolos del notario Marti Moliner (1633-1650), Alicante, 1983, p. 272, n. 224; y «Relacions económiques entre el País Valencia i Europa durant l'edat moderna: Aproximació al cas d'Alacant», en Pedralbes, 18(1998), p. 15-24.

5. J. ISRAEL, La República Holandesa y el mundo hispánico, Madrid, 1997. 
Pienso que a ello contribuyó la beligerancia de España, pues una pragmática de principios de 1623, publicada el 20 de mayo, tocó el nervio del comercio levantino al prohibir la importación de drogas y especias de Asia oriental por los ingleses, con cuya nación aún había paz.

En este repentino contraste hay que tener en cuenta precedentes poco conocidos, como fueron la atracción de los ingleses por Alicante (1607) y la competencia con Cartagena.

De hecho, podemos decir sin asumir grandes riesgos que Alicante se caracterizó durante el siglo XVII por la importancia de sus comerciantes ingleses, mencionando a Amadis, Balon, Basset, Blundell, Stripley, Garret, Guildon, o Paulin para este periodo, algunos de ellos favorecidos por su condición de católicos (Basset, Blundell y Paulin), quizá asimilables a otros grupos de exiliados, como el de los bretones ${ }^{6}$.

Se trataba de un grupo muy bien relacionado con los italianos (Bargali y Rivanegra formaban una compañía de comercio que compraba pimienta asiática en $1623^{7}$ y Francisco Imperial Jobardo, hijo de un genovés, era cónsul de Inglaterra y tenía buenas relaciones con Garret y otros ${ }^{8}$ ) y franceses (Nicolau Estella, bearnés; Pablo Salafranca, alicantino pero del mismo origen ${ }^{9}$ ).

La pragmática de prohibición de la pimienta provocó una larga crisis (1623-1624) que precedió a la primera guerra de Felipe IV con Carlos I de Inglaterra (1625-1630), pero la interdicción del comercio con las Indias Orientales denotó el fracaso del control del comercio holandés e inglés, pues Stripley consiguió vender ocultamente parte de la pimienta desembarcada. Se repetía una situación parecida a la de 1585-1604, pero ahora más grave, pues el transporte marítimo había pasado a ser predominantemente inglés, tras la interrupción de la Tregua de los Doce Años con Holanda (1621).

De hecho, la aplicación de la pragmática (octubre de 1623) atrajo las protestas de muchos, tales como diputados y procuradores de ciudad y comercio de Alicante, baile de Alicante y receptor de la bailía general ${ }^{10}$, Junta patrimonial de Alicante y su

6. J. J. RUIZ IBÁÑEZ, «Entre Dios y los hombres: Los refugios políticos en la Alta Edad Moderna Europea», en M. GONZÁLEZ JIMÉNEZ et al. Acogidos y rechazados en la historia, Valladolid, 2005, p. 35-84, cfr. 56.

7. Archivo de la Corona de Aragón (ACA), Consejo de Aragón, CA, leg. 603, 12/2 y 22 Memoriales de Pedro Martínez de Vera, baile de Alicante (5-5-1623 y 7-2-1624). El 16-10-1623 llegaron 2 navíos con 60 sacos de pimienta para Stripley y Guillermo Paulin.

8. V. Montojo Montojo, «Francisco Imperial Jobardo», en El Salt (La Revista-Instituto Alicantino de Cultura Juan Gil-Albert), 5 (2005), p. 40-43; y «Guerra y paz bajo Felipe IIl: El comercio del Levante español y sus relaciones clientelares, familiares y profesionales»), en Crónica Nova, 31 (2005), p. 349378.

9. Hijo o nieto de un comerciante francés de Beárn (Barón de Finestrat, Nobiliario alicantino, Madrid, 2003, p. 319), fue síndico de los negociantes alicantinos en 1641 (ACA, CA, leg. 882, 110/4-5 Carta de Marco Antonio Bisse al rey (28-5-1641).

10. Pedro Martínez de Vera, casado con Ana Imperial, hermana del mencionado Francisco Imperial (A. Arqués Jover, Nobiliario alicantino, Alicante, 1966, p. 59; Barón de Finestrat, op.cit., p. 202). 
receptor de rentas reales; jurados de Valencia, pues otro navío inglés entró en el Grao de Valencia" ${ }^{1 !}$

Esta oposición, que derivó en un conflicto de jurisdicción, es comprensible, pues se enfrentaban intereses muy arraigados, como la vinculación entre la importación de especias y drogas con los recursos fiscales de las distintas administraciones real, regnícola y municipal y los arrendamientos de las salinas de la Mata (Juan Andrea Carro, capitán de uno de los navíos que fueron detenidos en Alicante el 16-10-1623, pretendió licencia de sacar sal de la Mata, Stripley arrendó las salinas en 1623) ${ }^{12}$.

La pretensión de controlar el tráfico de la pimienta a través de la alhóndiga de Lisboa era irrealizable según los alicantinos, pues ellos se surtían del tránsito de la flota inglesa hacia las escalas del Levante mediterráneo, que les proporcionaba además anascotes, holandas, lienzos, paños, perpetuanes, ropas y sargas; y desde Alicante se abastecía de drogas, especias y textiles a los reinos de Mallorca, Murcia (Castilla) y Valencia. Este tráfico permitía la exportación de productos alicantinos (almendra, anís, barrilla, jabón, matalauva, pasa y sosa) y gracias a todo ello se recaudaban derechos aduaneros, ya que tanto los vecinos de Alicante como los de muchas poblaciones valencianas estaban exentos de tales impuestos y el comercio inglés ( 8 o 9 navios anuales) proporcionaba 16.000 ducados a las rentas reales, otros 16.000 ducados a la Generalitat valenciana y 18.000 ducados a las sisas municipales ${ }^{13}$. Ante tal situación conflictiva, los arrendamientos de las sisas municipales se redujeron en 2.700 libras con respecto a $1622^{14}$ : no se ofrecían por ellas 3.000 libras.

La presión de la administración central para impedir la entrada de barcos con especias orientales, que fue dirigida a través del virrey de Valencia, tuvo como contradicción el hecho de que fuera orquestada por el Consejo de Guerra, orillando al de Aragón, que tenía derecho de sobrecarta ${ }^{15}$, lo que permitió apelar a Stripley, el mercader inglés más perjudicado, por haberle tenido en cárcel común, quitado sus libros de cuentas y otros abusos.

11. Guillermo Garret, mercader inglés residente en Alicante, quería comprar de orden de Paulo Antonio Juliani, mercader florentino de Valencia, a Tomás Transfil, capitán inglés, pimienta y mercancía por valor de 8.000 libras, que hubiera dado 400 libras de dret d'aduana (ACA, CA, leg. 603, 12/46 Memorial de Lorenzo Ivorra n. 21 (18-3-1624). No se dejó desembarcar pimienta a un navio en el Grao de Valencia (ACA, CA, leg. 603, 12/5 Consulta de la pimienta (20-1-1624).

12. Stripley o Stribyl subió 400 libras el arrendamiento de las salinas de la Mata, en total 3000 ducados (ACA, CA, leg. 603, 12/13 Carta de Pedro Martínez de Vera a Nicolás Mensa (9-2-1624).

13. ACA, CA, leg. 603, 12/21 Carta de Alicante a Felipe IV (7-2-1624). Pidió que se tratara con suavidad a la nación inglesa, a causa del altercado ocasionado por el doctor Jerónimo Sanz, asesor del gobernador, contra Strebihil, pues se estaba subastando el derecho mayor de la mercadería. Y 12/28: Discurso hecho por lo que se puede colegir haya movido la mente de Su Majestad a mandar que en la Corona de Aragón.

14. ACA, CA, leg. 603, 12/4 Carta de Alicante a Felipe IV (14-3-1623).

15. ACA, CA, leg. 603, 12/23 Carta del marqués de Povar, virrey de Valencia, a Nicolás Mensa, secretario de Valencia en el Consejo de Aragón (9-4-1624). 
Pero a finales de 1623 el síndico del consell y jurats de Alicante denunciaba que algunos comerciantes extranjeros alicantinos se trasladaban a Cartagena. Según los jurados de Alicante «así este rigor como por esta novedad de dicha inhibición están todos los mercaderes y tratantes tan alterados que, además de haberse causado hasta hoy grandísimos daños a los derechos reales y de esta ciudad, se esperan mayores si no se acude con pronto remedio, porque siendo este puerto el almacén de este reino y de los circunvecinos, es fuerza cesar el trato sin el cual esta tierra quedará perdida, porque no tiene otros réditos sino los que proceden del trato mercantil».

Casi veinte años después (1641) hay indicios de que fracasaba la misión de Marco Antonio Bisse, veedor del comercio o contrabando en Alicante y asesor ordinario del gobernador de Orihuela, y de Valentín Elder, su ayudante, pues barcos que se manifestaron ingleses, pero que eran de Francia (Saint Maló) y Holanda, habían desembarcado pimienta, clavo y ropa de contrabando, así como habían cargado aceite, almendrolón, anís, pasa, vino y otras mercancías con destino oficial para Inglaterra y Génova, pero que descargaban en Saint Maló o Marsella, pues los oficiales reales no les pedían responsiva o registro y habían llevado más de 200 cabos de esparto fabricado en Alicante a Marsella, para la armada francesa ${ }^{16}$.

Por lo tanto, la política de fomento del comercio chocaba con la acción gubernativa contra la introducción de mercancías extranjeras, encauzada a través de la Junta del Almirantazgo (1625), pues muchos de los comerciantes de Alicante eran extranjeros o de origen extranjero, quienes precisamente recibían y reexpedían las mercancías repentinamente fraudulentas. Entre estas otras medidas estuvo la instauración del almirantazgo en Alicante, con la extensión de la jurisdicción de la Junta del Almirantazgo al Reino de Valencia en $1628^{17}$.

Por otra parte, los comerciantes constituían un grupo fundamental para las necesidades sociales del rey y sus oficiales (recaudaciones fiscales, suministros militares), como también para las autoridades locales y las poblaciones (abastos, arrendamientos de impuestos, crédito), y más aún en una época de guerra como fue el reinado de Felipe IV. De aquí su protagonismo e importancia como sujeto pasivo de nuevas contribuciones (acrecentamiento sobre los derechos de lanas y diezmos de los puertos aduaneros, nuevos derechos de barrilla y sosa y de pescados frescos, salados y salpresados), pero también como interlocutor en defensa de derechos relativos a exenciones y usos de monedas de cobre y de plata.

A partir de estas observaciones se pretende realizar en esta ocasión una revisión del estudio del comercio de Alicante (entendido como grupo mercantil) a partir del análisis de las fuentes archivísticas utilizadas hasta ahora, para hacer una aportación por medio de otras fuentes documentales y sobre todo de un enfoque microhistórico y nominativo.

16. ACA, CA, leg. 882, 110/1-3 Cartas de Valentín Elder y Marco Antonio Bisse (12-5-1641 y 19-5-1641). 17. J. CASEY, El Reino de Valencia en el siglo XVII, op.cit., pp. 99-103. 


\section{LAS FUENTES ARCHIVÍSTICAS Y SUS PRODUCTORES}

El comercio de los puertos de Levante como Alicante y Cartagena en el siglo XVII se ha estudiado hasta ahora aisladamente y a través del análisis de algunas fuentes archivísticas, como los derechos sobre la exportación de lana, los registros de entrada de barcos del primer cuarto del siglo XVII y la documentación notarial de Cartagena, registrándose un periodo de crecimiento de la exportación de lanas entre 1575 y $1621^{18}$ y de reducción de la contribución fiscal de la aduana entre 1601 y $1647^{19}$.

Nos hemos guiado, para el estudio del comercio de Alicante, por las siguientes fuentes:

1) Protocolos notariales de Martí Moliner, de Alicante, notario de una tesorería del reino, de los años $1633-1650^{20}$.

2) Protocolos notariales de Cartagena, en especial de Simón García Angosto, escribano de lanas, y Lucas Moreno, así como algunos de Yecla ${ }^{21}$, de los años 16211665.

A diferencia de Alicante, se conservan numerosos registros notariales de Cartagena a partir de 1588 (hay también dos sueltos, de 1558-1559 y 1577-1578), que ya en el siglo XVII incluyen diferenciados cuadernos específicos de obligaciones de pagos de los derechos impositivos de lanas (años 1607-1608, 1627-1634, 1640-1641, 16591665, 1694-1697). Estos cuadernos eran registros de los escribanos de rentas reales, que se inician con Simón García Angosto a partir de 1627 para los derechos de lanas de Cartagena, para el derecho de la barrilla y sosa en 1660 , aunque también y con mayor continuidad desde 1656 para todas las rentas reales del Reino de Murcia, dependientes de la Superintendencia de Rentas Reales.

De su análisis obtenemos una imagen del giro comercial mediante diversos tipos de contratos, como asientos, cartas de pagos, cesiones, fletamientos, obligaciones y poderes. Estos contratos notariales hechos en Cartagena muestran una mayor diversidad de la actividad de los alicantinos.

La documentación notarial de Alicante que se ha conservado es muy poca, a causa de su pérdida en los bombardeos de 1691 y 1708 , pero la que ha sobrevivido no se ha estudiado en lo que se refiere al comercio. No obstante, puede sacarse provecho de

18. J. ISRAEL, «Spanish Wool Exports and the European Economy, 1610-1640», en The Economic History Review, $2^{\text {a }}$ serie, 33/2 (1980), p. 193-211. H. LAPEYRE, El comercio exterior de Castilla a través de las aduanas de Felipe II, Valladolid, 1981, pp. 184-191. V. Montojo MonTojo/ F. MAESTRE DE SAN JUAN PELEGRín, «Las relaciones comerciales entre el Reino de Granada y el Reino de Murcia en la Edad Moderna», en M. Barrios Aguilera/ Á. Galán Sánchez (eds.), La historia del Reino de Granada a debate. Viejos y muevos temas. Perspectivas de estudio, Málaga, 2004, 281-299, y «Los comerciantes de Cartagena y su actividad en Huéscar en la segunda mitad del siglo XVII», en J. P. DiAZ LóPEZ ed. Campesinos, nobles y mercaderes (Huéscar y el Reino de Granada en los siglos XVI y XVII), Granada, 2005, p. 93-109.

19. E. SALVADOR ESTEBAN, «La 'frontera' intrarregnícola valenciana y su impacto en las instituciones reales. El ejemplo de las dos bailías generales», en Pedralbes, 13 (1993), p. 11-23, cfr. 18.

20. A. Alberola RomÁ, Catalogación de los protocolos del notario Martí Moliner (1633-1650), op. cit.

21. J. BlázQuez Miguel, Yecla en el siglo XVII, Yecla, 1988. 
la combinación del estudio de la de muy escasa de Alicante con la muy abundante de Cartagena, esta última para el reinado de Felipe IV, cuando se concentra la mayor parte de las informaciones con que contamos sobre los comerciantes de Alicante en protocolos notariales de Cartagena.

\section{CARACTERÍSTICAS GENERALES DEL COMERCIO EN LOS PUERTOS LEVANTINOS}

Una parte importante de la funcionalidad del comercio de Alicante y Cartagena estaba en las actividades marítimas de exportación e importación, en que predominaban de un lado las materias primas textiles y tintóreas y de otro los cereales, el pescado, las especias y las manufacturas textiles y férricas. Por lo tanto, podemos señalar varios productos comunes al comercio exterior de Alicante y Cartagena:

+ Alimenticios:

Aunque en ellos se elaboraban anís, pasas y turrones, fundamentalmente se exportaban:

- aceite (andaluz y mallorquín),

- cebada,

- sal, y sobre todo

- vino,

y se importaban:

- trigo (Italia, Francia mediterránea), y

- pescado salado o salazones del Atlántico Norte ${ }^{22}$.

+ Textiles y tintóreos:

- almagra,

- esparto,

- lana y

- seda.

Alicante era para Livorno el gran puerto de procedencia de la seda murciana ${ }^{23}$, pero otros puertos de Italia (Génova, Venecia) eran sobre todo receptores de la lana exportada desde Alicante y Cartagena, que desde 1575 era superior a la que salía por el Cantábrico y por Andalucía, pero experimentó una crisis coyuntural en 1617-1618, en torno al conflicto diplomático con Venecia, y otra más duradera a partir del inicio de la guerra con Holanda (1621), a causa sobre todo de la falta del transporte marítimo

22. F. Figueras PaCheCo, El Consulado Maritimo y Terrestre de Alicante y Pueblos del Obispado de Orihuela, Alicante, 1957, p. 30. E. GIMÉNEZ LÓPEZ, Alicante en el siglo XVIII: Economía de una ciudad portuaria en el Antiguo Régimen, Valencia, 1981, p. 243; «Dos décadas de estudios sobre el comercio valenciano en la edad moderna», en Revista de Historia Moderna, 6-7(1986), p. 193-206; y «El puerto en la Edad Modema», en F. MORENO SÁEZ, Historia de Alicante, Alacant, 1989, I, p. 306-310.

23. F. Braudel/R. Romano, Navires et marchandises à la entrée du port de Livourne, 1547-1611, París, 1951, pp. 47-48. 
holandés, que se agravó con la pérdida de las marinas mercantes bretona e inglesa por causa de otras guerras con Francia (1628-1631) e Inglaterra (1625-163024.

+ Vegetales y derivados:

- barrilla y

- jabón.

Cartagena había sido el gran puerto de salida del alumbre murciano en el XVI y también de la barrilla hasta principios del XVII, pero también Alicante se convirtió en puerto exportador de almagra y sobre todo de barrilla y sosa, estos últimos productos cada vez más abundantes en Alicante hacia 1630, pero también eran sedes de fábricas de jabón, cuya exportación se realizaba tanto en Alicante (a partir de 1565), como en Cartagena (desde 1580$)^{25}$.

Otra parte fundamental de la función mercantil se encuadraba en el comercio interior y se desglosaba en distintas actividades o servicios:

- Abastecimientos urbanos: contratos u obligaciones de abasto, acompañadas de fianzas.

La provisión de alimentos y manufacturas requería numerosos asientos o contratos de provisión.

- Crédito rural y urbano, tanto por medio de obligaciones de pago como de censales o censos.

- Suministros al ejército y la marina militar o armada real: asientos con las proveedurías.

Se trataba, en definitiva, de ciudades con actividades en cierto modo comunes o parecidas, que inducían negocios en los reinos de Granada (Almería, Almuñécar, Málaga, Motril, Salobreña) y Valencia.

\section{LAS REDES COMERCIALES DE ALICANTE. COMPOSICIÓN NACIONAL Y COMPAÑÍAS}

La guerra con Holanda (1621) dio lugar a la sustitución parcial de holandeses por flamencos, tanto en el comercio como en el transporte ${ }^{26}$ y sobre todo por los comerciantes y transportistas ingleses.

Un ejemplo de la influencia de la guerra de Holanda en el transporte lo da el fletamiento del navío San Esteban, anclado en la playa de Alicante, del capitán también flamenco Juan Habaut, de 1800 salmas, por Pedro Coch a Aqustín Panés, mercader genovés vecino de Cartagena, con el fin de embarcar en esta última ciudad lana y barrilla con destino a Génova: hasta 3 o 4000 quintales de barrilla y 400 sacas de

24. E. GRENDI, La repubblica aristocratica dei genovesi: Politica, carità e commercio fra Cinque e Seicento, Génova, 1987, p. 342. F. BRAudeL/ P.JEANnIN/ J.MEuvreT/ R. ROMANO, «Le declin de Venise au XVIIe siècle», en Aspetti e cause della decadenza veneziana nel secolo XVII, Venecia, 1961, pp. 23-86.

25. E. GiMÉNEZ LÓPEZ, «Auge y ocaso de las plantas barrilleras en el Mediterráneo españob», en Canelobre. Revista del Instituto Juan Gil-Albert, 6 (1986), p. 51-56.

26. A. DOMinguez. ORTIZ, «Guerra económica y comercio extranjero en el reinado de Felipe IV》, en Hispania. Revista Española de Historia, XXIII, 89 (1963), p. 71-110, cfr. 74 
lana, a cargar en Cartagena o Mazarrón, los fletes a 2 reales y cuartillo el quintal de barrilla y 22 reales la saca de lana. El navío tardaría 3 o 4 días en salir de Alicante, la barrilla sería entregada 4 días después y la lana en otros 24 días. Fueron testigos Adán Vangermes, flamenco residente en Cartagena, además de los genoveses Iusepe Ansaldo y Agustín Dardalla ${ }^{27}$. Hay que destacar sobre todo que el fletamiento del barco fuera contratado en Cartagena, estando situado en Alicante, cuando era más frecuente que se contratara en Cartagena con destino a Alicante, pues podía suceder que barcos procedentes de Orán llegaran a Cartagena de vacío y que su carga debiera ser completada en Alicante.

Había, por lo tanto, fuertes relaciones con Italia (Génova, Livorno y Venecia) y Francia (Marsella, puerto principal de Provenza, y Bretaña a través de Saint Maló) y algo menores con Inglaterra (Londres), Holanda (Amsterdam) y Alemania (Hamburgo).

Como lógica consecuencia de esta confluencia de intereses económicos, en Alicante predominaban claramente los comerciantes italianos, en especial los genoveses, con una tradición muy importante desde mediados del XVI. A ellos se añadieron florentinos, milaneses, napolitanos y venecianos.

Podemos observar a partir de las escrituras notariales de Cartagena referentes a Alicante que destacaba un grupo de origen genovés y milanés (Ansaldo, Canicia, Imperial, Isola, Moxica, Musiteli, Nicolini, Paravecino), como en Valencia hasta $1575^{28}$, cuyos negocios estaban relacionados con los asientos de la Proveeduría de Armadas y Fronteras de Cartagena (pólvora), las exportaciones marítimas (barrilla, esparto, lana y seda), la importación de pescado, las deudas a portugueses que administraban rentas (lanas).

De ambas fuentes se deduce que los naturales de Italia llevaban muchos años en Alicante, ya desde mediados del XVI, mientras que a los de Inglaterra les fue permitido por Felipe III desde 1604.

Algunos de estos comerciantes tenían negocios en Cartagena y Murcia (lusepe Paravecino), relacionados con el comercio del pescado, o estaban emparentados con comerciantes de Cartagena (Ansaldo, Baldasano, Canicia, Imperial, Paravecino).

Si recurrimos a una comparación con el comercio de Cartagena vemos que se daba una situación parecida en cuanto a la composición nacional del comercio. Como característica singular de esta época hay que destacar la presencia inglesa, muy relacionada también con el comercio de pescado, en que sustituyeron a los bretones, sobre todo a partir de 1628, en que la guerra con Francia fue casi continua hasta 1659. Este hecho les permitió asimismo introducir otros productos que eran necesarios para la guerra, como el azufre, es decir, intervenir en los asientos de provisión de las armadas reales, lo cual nos lleva al análisis de este aspecto, tan relacionado con los puertos levantinos de Alicante y Cartagena por su proximidad a Berbería (presidios de Orán y

27. Archivo Histórico Provincial de Murcia (AHPM), Prot. 524I, fs. 96v-97v.

28. E. SALVADOR ESTEBAN, «Mercaderes extranjeros en la Valencia de los siglos XVI y XVII. Entre la atracción y el rechazo», en Congreso Internacional La Burguesía española en el Antiguo Régimen (Madrid, 1991), Valladolid, 1996, p. 1137-1155, cfr. 1143. 
Mazalquivir) y por su posición de escala entre Italia y los puertos del poniente español (Gibraltar, Cádiz).

Analizaremos a continuación algunos ejemplos de compañías familiares genovesas con implantación en una y otra ciudad.

\subsection{Los comerciantes de origen italiano.}

+ Los Imperial-Digueri y Prebe-Pelerán: de Alicante a Cartagena.

Frente a la manida idea de que Alicante prosperó a partir de 1550 gracias a la inmigración de italianos procedentes de Cartagena, hoy se puede asegurar que Cartagena fue mucho más un núcleo mercantil fundamentalmente receptor de inmigrantes italianos, sobre todo entre 1570 y 1620 .

Los Imperial, como otros naturales de Génova, realizaban fundamentalmente exportaciones de lana, siguiendo una tradición ya antigua en 1610, pues en 15691570 Bartolomé y Ambrosio Usodemar, vecinos de Cartagena y Murcia, exportaban lana de añinos y barrilla por Alicante hacia Génova, en relación con otros mercaderes de Alicante, como Nicolao Cigala y Jerónimo Escipión ${ }^{29}$, y también con Esteban Lomelín de Huéscar ${ }^{30}$ y quizá con los Usodemar de Valencia ${ }^{31}$. También a final del siglo XVI algún genovés de Cartagena mantenía tratos comerciales esporádicos con Valencia, como Pelegro Castellón con Glaudo Mateu ${ }^{32}$. Otros italianos, como Juan Bta. Paravecino, estaban relacionados con el negocio sedero de Murcia en $1659^{33}$.

La compañia de los Digueri, Pelerán y Prebe, comenzada en 1614, obligó al desplazamiento de Vicente y Deodato Imperial de Alicante a Cartagena, y experimentó la desaparición de Juan Agustín Pelerán (1625) y Juan Bta. Prebe (1634), pero con su reanudación en 1625 adquirió una mayor importancia, al mismo tiempo que continuaba su vinculación en Alicante con otro hermano, Francisco Imperial, a quien se remitía a veces lana de Huéscar (Granada), para que la embarcara hacia Italia ${ }^{34}$.

La compañía de los Digueri en Huéscar fue una de las de Cartagena que comerció, además de con lana lavada en Huéscar, también con azúcar de Motril, Almuñécar y Salobreña, como lo hicieron también los Tacón. Entre 1608 y 1640 los hermanos

29. AHPM, Prot. 510, fs. 19 y 20; Archivo Municipal de Cartagena, Acta Capitular de 21-5-1572.

30. B. VINCENT, «Les Gênois dans le Royaume de Granade au XVIe siècle», en BELVEDERI, R. (ed.) Rapporti Génova-Mediterraneo-Atlantico nell'età moderna, Génova, 1990, p. 151-162, cfr. 157.

31. E. SALVADOR ESTEBAN, «Mercaderes extranjeros en la Valencia de los siglos XVI y XVII», op. cit., p. 1142.

32. E. SALVADOR ESTEBAN, La economia valenciana en el siglo XVI (comercio de importación), Valencia, 1972, p. 73. V. Montojo Montojo, «Mercados y estrategias mercantiles en torno a Cartagena en el siglo XVI y la primera mitad del XVII: un microanálisis», Cuadernos del Estero, 7-10 (1992-1995), p. 143-202, cfr. 168.

33. P. MirAlies MARTINEZ, La sociedad de la seda: Comercio mamufactura y relaciones sociales en Murcia durante el siglo XVII, Murcia, 2002, p. 249

34. V. MONTOJO MONTOIO, «El comercio con Andalucía Oriental: actividad de los mercaderes de Cartagena (siglos XVI-XVII)», en Chronica Nova, 24 (1997), 237-252. 
Deodato y Vicente Imperial aportaron, además de su trabajo, sus relaciones en Alicante, donde mantenían buenos contactos y parentesco con los Canicia de Franquís y los Pasqual ${ }^{35}$.

Francisco Imperial, aunque de padre genovés, tenía un gran arraigo en Alicante, pues accedió al gobierno de la ciudad y, entre otros oficios, detentó el consulado de Inglaterra. En 1627 era considerado caballero del Reino de Valencia, cuando facultó en Cartagena a Gerardo de Acosta, teniente del administrador general de los derechos de las lanas en los puertos de Castilla ${ }^{36}$.

Recibió además una merced en un oficio militar. Por otra parte, su hija Josefa casó con Andrés Prebe, su primo, hijo de Juan Bta. Prebe, y heredó una heredad en Rabasa, cerca de Alicante.

Del ejercicio de su oficio de cónsul de Inglaterra se desprenden los poderes concedidos a Guillermo Garret, inglés, y Pedro Canicia de Franquís, de origen genovés, que nos dan idea de la importancia de las relaciones entre comerciantes genoveses e ingleses, pues al último lo apoderó en 1630 para administrar el consulado de Inglaterra en Alicante. También Vicente Imperial fue cónsul de Inglaterra y Alemania, pero en Cartagena.

A la muerte de Vicente Imperial (1640), el licenciado Francisco Rocho de Montenegro, su yerno, alcalde mayor de Murcia, tutor de los hijos menores de Juan Bta. Prebe, dio poder a Juan Bta. Canicia de Franquís, vecino de Alicante, para recibir de los capitanes de dos naves una caja de tabíes de flores procedente de Génova, remitida por Pedro Antonio Tacón a los menores de Juan Bta. Prebe, y venderla. La vinculación de los Imperial y Prebe con los Canicia de Franquís se mantuvo más allá de la desaparición de los fundadores de la compañía de $1608^{37}$.

Deodato Imperial declaró en su testamento haber tenido cuentas con Guillermo Paulin, vecino de Alicante, hasta poco antes de su muerte. En 1634 Paulin apoderó a Deodato Imperial ${ }^{38}$ y en 1636 hubo que liquidar cuentas ( 30.000 reales), que Giles Fetiplas, mercader inglés residente en Cartagena, apremió a pagar a Juana Digueri, viuda de Deodato, correspondiente al negocio de importación de bacalao con mercaderes ingleses, como Tomás Cradoche y Mauricio Tanson de Londres, por 35.000 reales de plata por deuda de Agustín Panés y Ciprián Machavelo, genoveses de Cartagena, a través de Guillermo Parley, de Madrid ${ }^{39}$. Se trataba de un producto de consumo popular, pues la carne era de precio carísimo.

35. BARÓN DE FInESTRAT, Nobiliario alicantino, Madrid, 2003, p. 107.

36. AHPM, Prot. 5225, fs. 133v-134v, 11-10-1627. Agradezco algunas notas a F. Maestre de San Juan Pelegrín. 37. AHPM, Prot. 5334, fs. 248v-249v, 18-9-1642, cit. por V. Montojo Montojo/F. Maestre de San Juan Pelegrín, «Las relaciones comerciales...», op. cit., p. 295.

38. A. Alberola Romá, Catalogación de los protocolos del notario Martí Moliner (1633-1650), op. cit., p. 77.

39. AHPM, Prot. 5300, fs. 211-216, 18-6-1636 cit. por V. Montojo Montojo, «Mercados...», op. cit., p. 184. 
Esta importación de grandes cantidades de pescado inglés relacionaba a comerciantes de Cartagena (Deodato Imperial) con otros de Málaga (Adrián Páez, 1630) y el inglés Tomás Hespiche ${ }^{40}$.

Se puede deducir de estas notas que el restablecimiento de la paz con Inglaterra en 1604 y 1630 permitió a mercaderes y transportistas ingleses imponerse a otros grupos, como los franceses. De éstos los bretones habían monopolizado la importación de pescado entre 1580 y $1630^{4 i}$, pero quedaron excluidos durante los largos periodos de guerra de mediados del siglo XVII.

Por otra parte, Deodato Imperial se relacionaba con otros connacionales genoveses de Alicante y Cartagena, como Iusepe Ansaldo, de quien fue apoderado junto con Rafael Mucio, Bartolomé Lardón y otros genoveses de Cartagena ${ }^{42}$, pues era normal que se facultaran estos comerciantes para recibir mercancías, cobrar deudas u otras gestiones. Estas podían hacerse asimismo en sentido inverso, pues poco después Pelegro Sibori, genovés de Cartagena, daba poder a Lorenzo Sibori, su hijo, y a Juan Bta. Socolo, genoveses de Cartagena, para ajustar cuentas con Juan Bta. Verdín, de Alicante, por dinero y mercancías que se debieran ${ }^{43}$.

Con los Imperial y Prebe de Alicante y Cartagena tuvieron también que ver Francisco Tallacarne, Juan Francisco Casione, Pantaleón Lardón, Ambrosio Blanco y Bernardino Bensio, que en 1635 encargaron al inglés Nicolás Huerlestón, capitán de un navío, que cargara mercancías en Alicante para Venecia, y en 1636 fletaron una nave al capitán Lamberto Picher para llevar ropa y mercancías desde Venecia a Alicante y volver con barrilla y lana. Otras veces estos barcos llegaban a Cartagena con sardina irlandesa ( 102 botas en 1637) para Juan Bta. Canicia de Franquís y Francisco Imperial. Este, aunque trasladado a Cartagena por asuntos militares, mantuvo sus negocios y bienes administrados primero por Pedro Canicia y después por su yerno Andrés Prebe, hijo de Juan Bta. Prebe, casado con Josefa Imperial, su hija, y por Pedro Martínez de Vera, casado con Ana Imperial, su hermana, como también los administró Agustín Ignacio Prebe. Pedro Canicia arrendó como procurador de Francisco Imperial la heredad de la Torre, una de las tres de Rabassa, a Francisco Torregrosa, en 1642. Tanto Andrés Prebe y Josefa Imperial como Pedro Martínez de Vera, caballero de Alicante, fueron apoderados en 1644 de Francisco de Montenegro, tutor de los hijos menores de Juan Bta. Prebe, y Martín Colomina vendió una heredad situada en el Clot de Rebolledo a Francisco Imperial, aún residente en Cartagena. Josefa Imperial y Andrés Prebe, temporalmente vecino de Cartagena, otorgaron respectivamente ápoca y poder a don Juan Coloma Pérez Calvillo, conde de Elda, y al doctor Jorge Martí, vecino de Madrid, y ambos otra ápoca a doña Josefa Remiro de Espejo. Al año siguiente Agustín

40. AHPM, Prot. 5298, 4-4-1630, f. 107 cit. por V. MONTOJO MONTOJO, «Mercados...», op.cit., p. 165.

41. V. MONTOJO MONTOJO/J. J. RUIZ IBÁÑEZ, «Le comunità mercantili di Genova e Saint Malo a Cartagine, porta della Castiglia), en G. Motta, ed. Mercanti e viaggiatori per le vie del mondo, Milán, 2000, 75-90.

42. AHPM, Prot. 5324, f. 529v, 29-11-1632.

43. AHPM, Prot. 5325, f. 22v, 11-1-1633. 
Ignacio Prebe, vecino de Cartagena, nombró procuradora a Josefa Imperial, a quien además se obligó a pagarle 2.000 libras que había prometido a Andrés Prebe. Aún en 1649 el jesuita José Bonari expedía ápoca, como procurador de Andrés Prebe y Josefa Imperial, a Manuel de Montesinos, pero en 1650 el mercader Tomás Sempere lo hacía sólo en nombre de Josefa Imperial, como también José Bonari, pues ya era viuda, en una cesión de derechos contra Manuel Montesinos a favor de Gaspar Moxica, mercader de Alicante ${ }^{44}$.

Con posterioridad a la muerte de Deodato Imperial se liquidaron otras de sus cuentas con Alicante, como prueba la carta de pago que otorgó Bartolomé Baldasano, vecino de Cartagena, a favor de Juana Digueri, viuda de Deodato, por 3.200 reales de plata que cobró en nombre de Juan Agustín Ansaldo, vecino de Alicante, cesionario del capitán Andrés Andresson de Noruega, capitán de navío, en virtud de una letra de cambio firmada de Richarte Reguill y Guillermo Beart, ingleses de Málaga ${ }^{45}$.

La documentación notarial de Cartagena es enormemente interesante, pues como veremos los ingleses Garret y Paulin eran los comerciantes más importantes de su nación.

Los negocios y relaciones de los Imperial manifiestan una pequeña parte de la actividad de los comerciantes genoveses e ingleses de Alicante, entonces principal puerto exportador de lana, según Jonatan Israel, aunque esta actividad fuera decreciendo al principio del reinado de Felipe IV, con la reanudación de la guerra de Holanda, que privó a Alicante de los transportistas holandeses, entonces los más importantes. De esta guerra con Holanda y de la de Francia salieron beneficiados los ingleses, siendo Alicante ciudad de residencia de algunos comerciantes británicos.

+ Los Ansaldo, Dardalla, Musiteli, Moxica, Paravaña y Paravecino:

Un ejemplo distinto

La presencia de los Ansaldo, Dardalla y Paravecino, genoveses, la advertimos antes en Cartagena y Murcia que en Alicante, lo cual es comprensible porque la documentación notarial de esta última ciudad es posterior. Jerónimo Ansaldo trabajó en Cartagena en los primeros años del XVII, donde tuvo varios hijos con Doralice Carro, quizá pariente de Lázaro Carro, comerciante de Alicante. Entre 1608 y 1614 nacieron Jerónimo, Juan Domingo, Magdalena y Juan Agustín Ansaldo, quien hacia 1630 se trasladó a Alicante, donde llegó a ser administrador de las salinas de La Mata, jurado y tuvo descendencia.

Los Ansaldo y los Dardalla tuvieron relación con los Imperial, dedicándose sobre todo a la exportación de lanas. Juan Bta. Dardalla y Marco Antonio Paravaña, de Alicante, y Iusepe Ansaldo y Agustín Dardalla, de Cartagena, formaron una compa-

44. A. Alberola RomA, Catalogación de los protocolos del notario Marti Moliner (1633-1650), op.cit, p. 94, $164,169,235,254,256-257,267,299: 1642,486 ; 1644,19,20,37,45,46,162 ; 1645,107,108 ; 1649$, $238 ; 1650,22,341$.

45. AHPM, Prot. 5300, f. 312, 25-9-1636. 
ñía desde 1625 hasta 1634 . Otorgaron fletes, seguros, cargazones, en relación con sus familiares de Génova y con asentistas de Madrid y mercaderes ingleses, como Jorge Juan Romena ${ }^{46}$.

En 1633 Juan Bta. Dardalla era representado en Alicante por Juan Bta. Verdín, mercader genovés, antes vecino de Cartagena, quien liquidó cuentas con Pelegro Sibori y Juan Bta. Socolo, genoveses de Cartagena, pero delegó su procuración en Iusepe Ansaldo, en cuyo nombre vendió esparto y pimienta. Sin embargo, era en realidad Marco Antonio Paravaña quien llevaba gran parte del trabajo de la compañía en Alicante, como ventas de atún, bacalao, castañas, papel, pimienta, queso salado, solimán y tabaco a vecinos de Alicante, Biar, Elche, Játiva, Novelda, Orihuela, Pego, Villajoyosa, Villena y sobre todo Yecla. Pero en 1634 Iusepe Ansaldo y Paravaña disolvieron la compañía, en razón de que su duración prevista era para 5 o 6 años. No obstante, Marco Antonio Paravaña continuó su actividad mercantil y obtuvo el reconocimiento de parte de la propiedad de 2 naves. Paravaña estuvo casado con Casandra Bogioni, hija de un mercader genovés establecido en Alicante (Artibaro Bogioni), y murió en 1642, pero arraigó en Alicante, hasta el punto de adquirir una finca en Mutxamel, en cuyas cercanías construyó una ermita junto con Pablo Jerónimo Ribanegra y Gaspar Suqueto, mercaderes socios ${ }^{47}$. Bojoni y Ana Quirós, su mujer, nombraron albaceas a Francisco Mojica y Pedro Vicente Rodríguez, sus yernos (1629) y dispusieron que fueran sepultados en la claustra de Ntra. Señora del Remedio, dentro de la Colegiata de San Nicolás ${ }^{48}$.

Al igual que los Imperial, pudieron llegar a Alicante bajo la protección de otro connacional ya instalado en ella, y así lo hicieron otros, pues eran frecuentes las relaciones tío-sobrino y suegro-yerno entre las compañías de estos comerciantes: de Bojoni, por ejemplo, eran también yernos Francisco Moxica o Mojica el viejo, comerciante asociado a Juan Musiteli, y Gaspar Suqueto.

En 1636 Francisco Moxica y Juan Musiteli formaban compañía de comercio con Iusepe Paravesino y Gaspar Suqueto, entre otros ${ }^{49}$. Eran todos concuñados.

Francisco Moxica fue un continuador no sólo de la actividad de Artibano Bogioni, su suegro, sino también de la de Pedro Vicente Rodríguez, su cuñado, que debieron morir poco antes de 1633 .

Entre estos comerciantes italianos de Alicante estaba Juan Musiteli, que en 1629 fue facultado por Jacome Codar, caballero de Orihuela, para cobrar 200 reales de plata doble a Juan de Morales, autor de comedias, y para recibir mercancías que se le remitieran $^{50}$. Consta también que adquirió lana en Yecla a María Azorín ${ }^{51}$.

46. A. Alberola Romá, Catalogación de los protocolos del notario Marti Moliner (1633-1650), op. cit, p. 65.

47. Ibidem, p. 139.

48. AHN, Nobleza, Someruelos, caja 5, documento 9 / Testamento de Artibaro Bojoni y Ana Quirós (9-41629).

49. A. Alberola Romá, Catalogación de los protocolos del notario Martí Moliner (1633-50), op. cit, p. 113. 50. AHPM, Prot. 5226, f. 201, 16-11-1629.

51. J. BLÁZQUEZ Miguel, Yecla en el siglo XVII, op. cit., p. 239 
Además de esto, Juan Musiteli y Marco Antonio Paravaña fueron los beneficiados por Carlos Caminati y Bartolomé Baldasano, en contratos de caución de rato con Domingo Batiferro, capitán de navío, para que cargaran 200 y 60 saquetas respectivamente de lana sucia y añinos con destino a Génova, a embarcar en Alicante ${ }^{52}$.

También podemos observar la pronta actividad en Murcia de José y Juan Bta. Paravecino, comerciantes de Alicante, en relación a Sebastián Fajardo Saavedra, al que a través de un intermediario (Francisco Bernal) le otorgaron carta de pago por valor de 1400 reales (1619).

Todos ellos prosperaron también socialmente, pues pudieron ser reconocidos caballeros o ciudadanos. Así Juan Agustín Ansaldo fue jurado en cap en Alicante, donde pleiteó para que el justicia y los jurados no se inmiscuyeran en la insaculación de nobles, que estaba reservada al rey, pero aquellos procedieron contra él, denunciándole por ocupar cargos que estaban reservados a los naturales del reino de Valencia, siendo él nacido en Cartagena ${ }^{53}$.

Por lo tanto, se trata de comerciantes y compañías que prosperaron en Alicante y Cartagena sin que puedan ser equiparadas otras de naciones diferentes, salvo pocas excepciones, como los franceses Junge y Poyo.

El comercio de la pimienta, en el que intervinieron los genoveses incidentalmente, estaba dominado por los ingleses desde que en 1621 lo perdieron los franceses y holandeses al entrar en guerra con España. El estudio de los Imperial, por otra parte, pone en evidencia la relación tan estrecha que había entre genoveses e ingleses, que llegó al parentesco.

\section{+ Los Lamberto, los Panés y los Rato}

El ya mencionado Musiteli mantuvo correspondencia con Juan Lorenzo Rato, de Cartagena. Los Lamberto (Agustín, Esteban y Juan Bta.), los Panés y los Rato participaron en la exportación de lana, pero diversificaron su negocio a otros productos, muy parecidos a los del radio de acción de Cartagena (alumbre, barrilla, esparto y excepcionalmente cereales), en la costa almeriense, de los que hacían objeto de fletamientos para embarcar en las Cuevas, Vera, Mojácar, La Carbonera y Almería con destino a Málaga, Marbella ${ }^{54}$, Sanlúcar o Lisboa, aunque en relación con mercaderes de Almería y Málaga. La embarcación de cereales en la costa almeriense por estos genoveses se dirigía a la provisión de alimentos a ciudades, flotas y tropas. Pero una diferencia fundamental era que la costa almeriense proveía de aceite a Cartagena y a muchas poblaciones del reino de Murcia e incluso de comarcas próximas, como las del valle del Almanzora o La Mancha ${ }^{55}$.

52. AHPM, Prot. 5300, fs. 276v-277r y $277 \mathrm{v}-278 \mathrm{v}, 29-8-1636$.

53. Archivo Municipal de Alicante, armario 3, caja 7, n. 3. Agradezco a Susana Llorens Ortuño su amabilidad en guiarme en el uso de este archivo. Ver también: A. ALBEROLA RomÁ, Jurisdicción y propiedad de la tierra en Alicante (ss. XVII-XVIII), Alicante, 1984.

54. N. Cabrillana, Almeria morisca, Granada, 1982, pp. 92-94.

55. V. Montolo Montolo, «Mercados...», op. cit., p. 165. 
Juan Bta. Lamberto, que llegó a Cartagena como un artesano, se convirtió en un hombre de negocios, quizá con su matrimonio con Clara Maldonado, hija de Lucas Maldonado, armero real, que le aportó en dote el oficio de cónsul de Francia en Cartagena. La consulta del nombramiento de Juan Bta. Maldonado como cónsul de Francia dio lugar a un informe sobre los cónsules extranjeros en los distintos puertos marítimos de España y, al cabo de unos años, al nombramiento en cada uno de un cónsul de las naciones extranjeras, que anulaba la presencia de cónsules por cada nación. Curiosamente en la relación que se hizo acompañando al informe, estaban ciudades como San Sebastián, Bilbao, La Coruña, Sanlúcar de Barrameda, Cádiz, Málaga, Valencia, pero no Alicante.

A finales del reinado de Felipe IV un hijo de Juan Bta. Lamberto obtuvo la correduría de fletamientos y una escribanía numeraria. No hubo, por lo tanto, una continuidad en el comercio.

Los Panés y los Rato, parientes, exportaban barrilla, además de lana, e importaban pescado inglés, por lo que Agustín Panés fue procesado por el Almirantazgo ${ }^{56}$, pero participaron asimismo en el comercio de Cádiz, aportando dinero para asegurar la flota de Indias ${ }^{57}$.

\section{+ Los Patucio, Ribanegra y Rizo}

Pablo Jerónimo Ribanegra tuvo actividad en 1634, nombrando procurador a Musiteli, y 1635-1636, vendiendo telas negras y sobre todo abadejo a vecinos de Tibi y Yecla. Es posible que fuera el mismo Ribanegra que estaba asociado a Pablo Jerónimo Bergali o Bargali, a quienes el doctor Jerónimo Sanz, asesor de gobernación, les requisó sus libros de cuentas, siendo la compañía más beneficiosa para los derechos reales de aduana, por lo que se acusó que esta incautación denigraba de descrédito a estos mercaderes $^{58}$. Pablo Ribanegra, junto con Paravaña y Suqueto, con los que debía tener parentesco, hizo edificar una ermita de la Purísima en la partida de Bon Any (Mutxamel). Tuvo compañía con Juan Bta. Patucio, su primo, a partir de 1642, vendiendo bacalao y trigo a numerosos vecinos de las poblaciones cercanas y sobre todo de Yecla (395 cahices por valor de 2765 libras), recibiendo cesiones de deudas, letras de cambio y cambios sobre la feria de Medina del Campo, proveyendo de dinero a las galeras del duque de Tursi y arrendando los diezmos. Fue también administrador de las salinas de la Mata (1645) y ambos apoderaron en este año a un alemán residente en Cádiz, falleciendo Rivanegra en 1649. Patucio se hizo cargo de las hijas de Rivanegra y de la compañía, siendo nombrado cónsul holandés (1649) y manteniendo negocios con Fernando Van Beuquen, flamenco, y Nicolás Barberini, residentes en Madrid $(1650)^{59}$.

56. A. Dominguez OrTIZ, «Guerra económica y comercio extranjero en el reinado de Felipe IV», op. cit., p. 82.

57. J. J. RuIz IBÁÑez/ V. MONTOJo Montojo, Entre el lucro y la defensa: Las relaciones entre la Monarquía y la sociedad mencantil cartagenera (comerciantes y corsarios en el siglo XVII). Murcia, 1998, p. 57.

58. ACA, CA, legajo 882, memorial de Pedro Martínez de Vera, baile de Alicante (5-5-1523).

59. A. Alberola RomÁ, Catalogación de los protocolos del notario Martí Moliner (1633-1650), op.cit,p. 197. 
Las comerciantes de Alicante de origen italiano negociaban sobre todo con lanas, relacionándose profesionalmente con otros comerciantes afines o parientes de Cartagena, hasta el punto de estar asociados con ellos, compartir unas mismas naves de transporte, o auxiliarse mutuamente ante el aislamiento que producía una epidemia o una guerra. Por otra parte, necesitaron del transporte de franceses e ingleses. Además, como consecuencia de su actividad crediticia, acumularon censals o censos, que para Alicante Martí Moliner refleja ampliamente por ser notario de la Tesorería del Reino, de la que recibieron dinero Paravaña y Paulin, y adquirieron propiedades rústicas. Dotaron a éstas de ermitas y colaboraron con cofradías (Juan Bta. Paravecino fue mayordomo de la de la Purísima Concepción) y conventos, donde ingresaron algunos de sus hijos.

\subsection{La inmigración francesa e inglesa}

Cuando en 1623 se consultaba la creación de la compañía privilegiada de Levante, se consideraba la posibilidad de permitir que los extranjeros continuasen con la pesca del coral en Cerdeña, pues proporcionaba un buen ingreso fiscal, así como se reconocía que las drogas o especias que llegaban a la Corona de Aragón se traían «por manos de franceses y otros extranjeros, de Alejandría ${ }^{60}$.

Se aprecia por la documentación notarial alicantina que algunos genoveses comercializaban especias en la década 1631-1640, pero los ingleses lo hacían ya antes de 1625, en que empezaron las represalias contra ellos, y eran los franceses quienes lo hacían anteriormente, junto con los portugueses. Entre los franceses que se habían instalado en Alicante y Cartagena podemos señalar a Honorat Berge, Juan Beuli, Nicolau Estella, Francisco Martel, Pedro Quirant o Tirant, Luis Rigau y Juan Bta. Sebeli, en Alicante, y a Gabriel y Juan Bta. Cue, Francisco Grave, Lorenzo Grout, Joselín Hazou y Juan del Poyo en Cartagena, y entre los ingleses a Reinaldo Amadis, Juan Ballon, Antonio Baset, Guillermo Blunden, Richard Carey, Guillermo Garret, Nicolás Geferin, Enrique Guildon, Juan Len, Guillermo Paulin, José Quent y Ricardo Randal en Alicante y a Giles Fetiplas, Agustín Quendal y Roberto Pol en Cartagena.

Guillermo Paulin residió en Alicante ya antes de la guerra con Inglaterra de 1625-1630, pues él y Agustín Stripley fueron los grandes perjudicados por la crisis de 1623-1624, cuando se prohibió la entrada de pimienta y drogas asiáticas que no fueran registradas en la aduana o alhóndiga de Lisboa, con gran perjuicio para el comercio y recursos fiscales alicantinos ${ }^{6 !}$. Era cuñado de Antoni Menet, mercader flamenco de Valencia, y ambos tenían mucho negocio en Madrid $^{62}$.

60. British Library, Egerton, Ms. 340, fs, 151-155 o 165-169, 26-11-1623, anexa a decreto de 11-12-1623.

61. ACA, CA, legajo 882, carta de Pedro Martínez de Vera, baile de Alicante (7-2-1624). Habían entrado 2 navíos ingleses el 16-10-1623 en Alicante, cuya carga de pimienta y clavos fue embargada por orden del virrey de Valencia. Se sucedieron continuas presiones y protestas: de la ciudad (jurados y universitat), del baile, del arrendador del derecho de aduana, etc.

62. Archivo del Reino de Valencia (ARV), Real Audiencia (RA), Procesos criminales, parte 2, caja 59, exp. 610. A favor de Paulin testificó Francisco Cuyper, mercader flamenco de Valencia. Agradezco la infor- 
Sus actividades se vincularon a negocios distintos en algún caso a los de los italianos, como la exportación de esparto y jabón, aunque también participaron en la de barrilla y lana. Sus tejidos de importación eran principalmente bretones (lienzos) y normandos (ruanes).

Entre estos franceses de Alicante parece destacar Pedro Tirant, quien se asoció a Luis Rigau para enviar mercancías a poniente y asumió deudas y fianzas de otros franceses, como Juan Hicar de Altea. En los años 1633-1635 abundaron las liquidaciones de cuentas de estos franceses, en algunos casos con Pedro Tirant, pero él también hubo de reconocer que una barca que estaba a nombre suyo y de Marco Antonio Paravaña era de este último, así como vendió bienes inmuebles a Paravaña, a causa de las deudas contraídas. Todo ello muestra un ambiente precario, que presagiaba la proximidad de la entrada en guerra con Francia. A pesar de ello, se constata que muchos franceses que vivian en poblaciones del interior negociaban a través de otros (Tomás Sempere) y que siguieron recibiendo mercancías, sobre todo lencería; vendiéndola en sus poblaciones, como Alcoy, tradicional centro textil, a interés del $6 \%$, pero esta venta por encargo denota que, como en Yecla, eran quizá más buhoneros que mercaderes. En cambio, algunos franceses que permanecieron en Valencia dominaron el comercio de tejidos ${ }^{63}$.

Guillermo Garret, a quien apoderó Francisco Imperial para los asuntos del consulado inglés de Alicante, fue uno de tantos mercaderes ingleses que importaban pescado y manteca, y estaba relacionado con otros, como Ricardo Carey o Ricardo Quer ${ }^{64}$. Al igual que Paulin y Agustín Stripley, también implicados en el contrabando de la pimienta de 1623-1624, se estableció en Alicante antes de la guerra de 1625-1630 y a su término volvió a la ciudad, donde destacó como proveedor de pescado de las villas castellanas del antiguo marquesado de Villena.

Guillermo Paulin fue quizá el más señalado de estos ingleses, pues destacó por la variedad de su actividad y su arraigo. En la primera figuraban, además del pescado, los seguros sobre barcos, las fianzas, los cambios sobre las ferias de Medina del Campo, la exportación de sal, o sus relaciones con Cartagena y Murcia. Además de vender pescado salado (bacalao) y ropa a vecinos de Alicante, Mutxamiel, Villena y Yecla, fue frecuentemente apoderado por patrones ingleses para cobrar deudas o recibir mercancías a embarcar (lana, por ejemplo). Por otra parte, adquirió sepultura y tierras en Alicante y de sus hijas, una, Elisabeth Anna, casó con un genovés de la ciudad, Pablo Vicencio Lomelín, y otra, Feliciana, ingresó en el Convento de la Sangre ${ }^{65}$. A diferencia de los clientes de Tomás Sempere, que eran franceses residentes en poblaciones alicantinas y valencianas, entre los de Paulin abundaban los castellanos, tanto de Cartagena como especialmente de Yecla, y algunos menos de Villena, entonces también del Reino

mación de Vicent Jiménez Chornet, Carolina Pérez y Sergio Urzainqui, archiveros, sobre estos procesos y otras series.

63. J. CASEY, El reino de Valencia en el siglo XVII, op. cit., pp. 84 y 101.

64. A. Alberola RomÁ, Catalogación de los protocolos del notario Martí Moline, op. cit, pp. 18-20 y 173.

65. Ibidem, 19, 30, 41, 78, 85, 90, 129, 166, 259, 263. 
de Murcia ${ }^{66}$. Estas poblaciones demandaban fundamentalmente pescado y, en menor medida, especias y ropa.

Algo parecido se puede decir de Antonio Basset y Guillermo Blunden por la larga duración de su actividad en Alicante y otras circunstancias.

Fue competencia de la Junta de ejecución de Proveeduría, una de las muchas de la época del conde duque de Olivares, lo referente a la provisión de alimentos a los ejércitos, actividad en la que participaron los comerciantes de Alicante y Cartagena, que actuaban a veces en compañía o con algún modo de relación que desvela su correspondencia, o la documentación notarial (poderes). Las sucesivas entradas de Inglaterra y Francia en la Guerra de los Treinta Años contra España, y las sublevaciones de Cataluña y Portugal (1640) obligaron a renovados esfuerzos de suministros a armadas y fronteras, en los que participaron los genoveses de Cartagena, sobre todo en la provisión de cereales, pero también de los ingleses.

En 1625, por ejemplo, un comerciante italiano de Alicante asentaba con los oficiales de la artillería de Cartagena el suministro de pólvora, y en los años 1630-1640 se dio también una participación inglesa, entre otras, como en el caso de la provisión de azufre para la fabricación de pólvora ${ }^{67}$, pero el protagonismo inglés fue aún más notorio en la importación del pescado salado.

Por otra parte, podemos documentar las relaciones entre los mercaderes ingleses de Alicante (Ricardo Carpe, Sansón Elen, Benjamín Eranle y Sansón Lane) y Cartagena (Valentín Elder, Giles Feliplas y Ricardo Randal), en 18-6-1640 (también entre Juan Musiteli y Juan Lorenzo Rato Rato, genoveses), a quienes podemos sumar Raimundo Lant y Agustín Quendal ${ }^{68}$, por razón de la correspondencia con motivo de la revuelta de Cataluña, pues se acusó no sólo el asesinato del virrey Santa Coloma y 42 caballeros, sino también la matanza de mercaderes extranjeros y el saqueo de sus casas, todo ello bajo la urgencia de proveer de cereales al ejército español, que se hacía entonces desde Cartagena. Su correspondencia manifiesta el horror que les supuso la noticia de las muertes de muchos comerciantes en el Corpus de Sangre ${ }^{69}$.

Se trató de un grupo de mercaderes que en algunos casos se establecieron permanentemente, pues se pudieron naturalizar por su condición católica (Paulin, Basset y Herne en Alicante, Fetiplas y Pol en Cartagena), a diferencia de los mercaderes y patrones transeúntes de Sanlúcar de Barrameda que en 1610 formaban la cofradía de san Jorge ${ }^{70}$.

En lo que se refiere a los bretones de Cartagena y sus relaciones alicantinas, el mencionado Joselín Haçou recibió en 1626 una carta de pago de Juan Figueroa, vecino

\footnotetext{
66. Ginés de los Ríos Muñoz, de Yecla, testificó también a favor de Paulin (ver documento citado en nota 51). Era regidor de Yecla en 1634: S. MOLINA PUCHE, La construcción de una élite local. Poder familia y redes sociales en la Yecla del siglo XVII, Murcia, 2003, p. 168.
}

67. V. MONTOJo, «Mercados...», op.cit., p. 184.

68. AHPM, Prot. 5430, f. 95, 7-4-1648.

69. Archivo General de Simancas (AGS), Estado (E), legajo 2664.

70. AGS, E, legajo 227. 
de Orihuela, por razón de 5060 reales librados en una cédula de cambio despachada por Jaime Talayero, vecino de Alicante, cambiados con Alonso Martínez de Vera sobre $\mathrm{Haçou}^{71}$. Se puede apreciar que la relación profesional entre Haçou y Talayero fue creciendo con el paso de los años. Hazou fue también exportador de jabón de Alicante, como lo habían hecho también otros de sus connaturales (Julián Junchee), negocio en que intervino Gabriel Cue, bretón residente en Alicante. En 1630, el patrón Pedro Angot, natural de Saint Maló, fletó a Haçou su navio, de 70 toneles, 6 piezas de artillería y 18 marineros, para embarcar 700 quintales de jabón en Alicante y llevarlos a Saint Maló ${ }^{72}$.

Juan del Poyo el viejo, casado en Cartagena en 1592, fue quien desarrolló una mayor actividad comercial, con escenarios tan remotos como Amsterdam y Hamburgo, y entre ellas la exportación de esparto de Cartagena, Mazarrón, Lorca y Vera (Almería), para lo cual se sirvió de colaboradores alicantinos, como Juan Díaz, Francisco Ibáñez, Vicente Molina y Juan Amat, que recibieron adelantos de dinero con la obligación de entregarle 100 millares de esparto en embarcadero de Mazarrón a 19 reales cada uno ${ }^{73}$, Jaime Amat se comprometió a entregar otros 100 millares de esparto de la marca mayor de Marsella, a 30 reales el millar ${ }^{74}$, y Gaspar Puerta otros 100 millares a 30 reales el millar $^{75}$. Otro contrato de otros 100 millares lo hizo con Bartolomé Celdrán, a 36 reales el millar, quien los entregaría en la cala del Leño y Piedramala de Mazarrón ${ }^{76}$.

\subsection{Los castellanos, valencianos y catalanes.}

Aparte de extranjeros había también castellanos, valencianos y catalanes interesados en el comercio de Alicante y Cartagena, quienes pudieron intervenir asimismo en el proyecto de una gran sociedad comercial, la Compañía de Levante, estudiada por Molas, con 2 cámaras, una en Barcelona y otra en Cartagena (1630).

Entre ellos podemos señalar a los alicantinos (Amat, Celdrán, Duart, Galant, Huerta, Iborra, Llácer y Oliver). Juan Galán o Galant negoció con el esparto y las almadrabas. Anteriormente a 1621, en 1611, concertó con Matolín Germín, francés de Olona, el fletamiento de un navío de 70 toneladas para cargar 60 millares de esparto en Mazarrón, hacer póliza de cargazón en Alicante y trasladarlo a Mallorca ${ }^{77}$. Antonio Bta. Llácer y Tomás Duart, mercaderes de Alicante, tuvieron negocios con Jorge Fernández de Olandilla, portugués residente en Murcia $^{78}$.

¿Qué relación podían tener estos vecinos de Alicante con el comercio foráneo de Cartagena y Murcia?. El mismo Bartolomé Celdrán, primero residente en Alicante, se

71. AHPM, Prot. 5225, f. 16v, 6-2-1626.

72. AHPM, Prot. 5226, fs. 75-76, 10-5-1630.

73. AHPM, Prot. 5225, fs. 12v-13v, 10-2-1625.

74. AHPM, Prot. 5225, f. 35, 23-2-1626.

75. AHPM, Prot. 5225, f. 71, 27-7-1627.

76. AHPM, Prot. 5225, fs. 112r-113r, 28-10-1626, cit. J. J. RuIZ IBÁÑEZ/V. MONTOJO, Entre el lucro, op. cit., p. 65 .

77. V. MONTOjo Montojo, «Mercados...», op.cit., p. 163.

78. AHPM, Prot. 902, fs. 443-444, 30-9-1627. 
declaró vecino de Marbella en 1634, cuando fletó en Cartagena las fragatas Nuestra Señora de los Remedios (porte de 160 quintales) y Nuestra Señora del Rosario, de los patrones Pedro y Antonio Martínez, vecinos de Cartagena, para transportar 1100 quintales y 700 arrobas de barrilla del cargadero de Garrucha (Vera, Almería) a Marbella, el flete a 4 reales el quintal ${ }^{79}$.

Por otra parte, jurados y comerciantes de Cartagena y Murcia recurrían a los mercaderes de Alicante para aprovisionarse de ropa y tejidos, que después vendían en sus ciudades de origen. Eran sus fuentes de aprovisionamiento, puesto que estaban en la primera línea de la recepción de las mercancías extranjeras.

Lorenzo lborra o Ivorra fue otro de los alicantinos, famoso por un memorial en el que junto con Jerónimo Claros y otros rechazaba la invitación del conde duque de Olivares a asumir el riesgo del transporte de la pimienta desde Lisboa hasta Alicante ${ }^{80}$. De Iborra constan algunas ventas de esclavos y vino. Estando en Cartagena, dio poder a Francisco Fillón, francés, vecino de Málaga, para que pudiera cobrar de Simón de Negro, también vecino de Málaga, lo procedido de 12 pipas de vino que le entregó en la ciudad de Alicante para que lo vendiera donde pudiera, así como para que otorgara carta de pago de lo que cobrara ${ }^{81}$.

Francisco Bernal pudo ser otro mercader alicantino. En 1619, siendo vecino de Alicante y estante en Cartagena, declaró que en nombre de José y Juan Bautista Paravecino, vecinos de la ciudad de Alicante, $y$ en virtud de poder que le fue otorgado ante Leonardo Martínez de Lillo, escribano de la ciudad de Alicante, en 18-7-1617, como cesionarios que eran de Nicolás Usay u Osay, en virtud de traspasación que se otorgó ante Ginés de Fulleda, escribano de la ciudad de Murcia en 5-10-1616, había recibido de Sebastián Fajardo Saavedra, de Murcia, 1.400 reales que debía a sus partes por la compra de 70 fanegas de trigo de mar, por lo que le otorgaba carta de pago ${ }^{82}$.

Se trata de unas muestras de un comercio de alimentos en el que participaban tanto comerciantes valencianos como italianos instalados en Alicante.

Sin embargo, del mismo modo que los comerciantes de Alicante extendían su actividad mercantil a Murcia, los de Cartagena lo hacían asimismo a Orihuela, dándose incluso la acción combinada de unos y otros, pues Jaime Alcaina, vecino de Alcoy, reconoció que había seguido pleito con Alonso Martínez Fortún, vecino de Cartagena, ante la justicia de esta ciudad, en razón de una partida de 140 arrobas de atún que le vendió, y habían ajustado las cuentas resultando alcanzado Alcaina en 24 reales y medio, entrando además 126 reales y medio y 20 arrobas de atún que Gaspar Cerdán, vecino de Alicante, le había dado a Martínez Fortún por cuenta de Alcaina, con lo cual cada uno estaba satisfecho de la parte que le tocaba. Otro ejemplo: Ginés Ortiz, yerno de Lario, vecino de Orihuela, estante en Cartagena, se obligó a pagar a Tomás

79. AHPM, Prot. 5299 , fs. $355-356$ y 359v-360r, 21 y $24-10-1634$.

80. J. CASEY, El Reino de Valencia en el siglo XVII, op. cit., p. 83.

81. AHPM, Prot. 5454, fs. 461 v-462r, 7-7-1619.

82. AHPM, Prot. 5454, 12-3-1619. 
Rato, genovés vecino de Cartagena, 1000 reales castellanos del valor de una partida de medias de estambre y otras cosas que le había vendido, en Cartagena ${ }^{83}$.

El mismo Ginés Ortiz, mercader vecino de Orihuela, estante en Cartagena, se obligó a pagar a Tomás Rato, genovés, vecino de Cartagena, 1657 reales y cuartillos por el valor de 10 piezas de bocacíes y 4 piezas de telillas, 44 pares de medias de estambre y otras menudas, a pagar en Cartagena a fin de agosto de 1619, y declarándose pasamanero, otros 605 reales a Pedro Antonio Tacón, también genovés vecino de Cartagena, por 28 piezas de tafetán que le ha vendido a 27 reales y medio la pieza, en moneda de plata doble, la mitad a fin de julio y el resto a fin de agosto ${ }^{84}$. En estos ejemplos Cartagena se muestra como ciudad residencia de genoveses que proveen a Orihuela de tejidos y textiles manufacturados.

Pero en este último tipo de productos manufacturados también intervenían comerciantes franceses de Cartagena, que se proveian de alicantinos, pues Juan Bentellat, residente en Cartagena, se obligó a pagar 300 reales a Gabriel Arnao, vecino de la ciudad de Alicante, por una partida de vidrio que le había comprado ${ }^{85}$.

En la fabricación del vidrio se utilizaba la barrilla. De hecho, la almagra, el esparto y sobre todo la barrilla se habian convertido en productos de exportación que sustituían al alumbre, cuya producción había decaído en el Sureste español a finales del siglo XVI. Los exportadores, como Gabriel Acharte, vecino de Marsella, afrontaban desde 1621 un nuevo derecho sobre la barrilla, como el de las lanas. El mencionado Acharte fletó la saetía Santa Ana, del también marsellés Bonifacio Parpán, para cargar barrilla en Cartagena con destino a Marsella ${ }^{86}$. Anteriormente, el barcelonés Jaime Garriga había fletado un barco del patrón Francisco González, vecino de Cádiz, para cargar 700 quintales de barrilla a entregar en Tarragona, Sitges o Barcelona, a 3 reales plata el quintal ${ }^{87}$.

Pero también cabe señalar la actividad de otros grupos distintos de comerciantes naturales como los aragoneses. Este fue el caso de Jaime Talayero, muy relacionado con algunos franceses.

En el comercio marítimo de Alicante participaron asimismo comerciantes castellanos de Cartagena y Mazarrón. De esta última población era vecino Antón Jiménez, quien en 1630 fletó una fragata de Miguel Ponce, vecino de Cartagena, para que transportara 30 quintales de higos de Alicante desde Cartagena al puerto de Mazarrón, $\mathrm{y}$ desde este último llevara 200 quintales de barrilla a Alicante ${ }^{88}$. El transporte de barrilla hasta Alicante por vía marítima no era infrecuente, a pesar de que predominaba su exportación directa desde Cartagena, tal como se ha hecho observar reiteradamente.

83. AHPM,. Prot. 5416, 17-7-1625 y 5358, f. 222, 20-6-1619. Sobre Orihuela, ciudad sedera: D. BERNABÉ GIL, Monarquia y patriciado urbano en Orihuela, 1445-1707, Alicante, 1990.

84. AHPM, Prot. 5358, fs. 230 y $230 \mathrm{v}-231 \mathrm{v}, 9-7-1619$.

85. AHPM, Prot. 5.413, f. 297, 23-3-1618.

86. AHPM, Prot. 5299, fs. 268v-269r, 31-7-1634.

87. AHPM, Prot. 5298, fs. 56r-57r, 13-2-1630.

88. AHPM, Prot. 5226, fs. 183v-186v, 5-11-1630. 
A principios de 1630, por ejemplo, Ginés Martínez, vecino y regidor de Cartagena, facultaba a Jaime Talayero, vecino y familiar del Santo Oficio de Alicante, para cobrar 45 sarrias de barrilla marcada que el primero cargó en el galeón San Jorge, de Esteban de Oliste, desde Cartagena para Venecia ${ }^{89}$. Recordemos que Esteban de Oliste fue uno de los promotores de la Flota del Mediterráneo.

\section{LA FLOTA DEL MEDITERRÁNEO Y LA RELACIÓN COMERCIAL EN ASIENTOS, FLETES Y LETRAS DE CAMBIO}

Este fue el marco de relaciones entre los grandes comerciantes de Alicante y Cartagena, pero también se ha de tener en cuenta el contexto de guerra generalizada para que se pueda explicar la formación de una compañía muy especial, la Flota del Mediterráneo, en Cartagena (1630).

Tras la reacción a la guerra de Berbería mediante el corsarismo español en 16091614 hubo un nuevo recrudecimiento bélico en 1617, con la derrota de una flota española, en Cabo de Palos, que salía para transportar soldados a Nápoles, con ocasión del conflicto diplomático con Venecia. De nuevo, a partir de 1621 hubo también guerra con los holandeses (Combate del Cabo de San Vicente, 1622) y con Inglaterra (ataque a Cádiz, 1625), a las que se añadió la de Monferrato con Francia (Casale, 1629). Fue entonces cuando grandes comerciantes de Cartagena y alguno de Alicante formaron la que llamaron Flota del Mar Mediterráneo, con el fin de defender el comercio entre el Levante español e Italia (1630).

Pudo ser esta flota un intento más de solucionar el problema de las navegaciones sueltas o el de la navegación en conserva pero con pocos barcos, como se hacía con Orán, pues el tráfico marítimo se había hecho más inseguro en la década de 1620 . Por una parte, el fracaso estruendoso de la salida de la expedición de transporte militar a Nápoles en 1617, que fue sorprendida en Cabo de Palos por una flota argelina, había servido de muestra de la debilidad defensiva del litoral de Cartagena. Por otra, algunos mercaderes genoveses de Cartagena sufrían en forma de averías la pérdida de una saetía capturada por los argelinos, que el tripulaba el catalán Jeroni Pibernat, vecino de Arenys de Mar, repercutiendo sobre Agustín Panés y otros, en $1630^{90}$. También tendió a hacerse en conserva la navegación desde Cartagena a Italia, incluyendo una escala en Alicante. Una situación así se dio por diversos motivos, no sólo por seguridad, sino también para completar el cargamento de los barcos, o por asociación mercantil.

A este problema hay que unir el estímulo y necesidad de la Monarquía para que se formaran escuadras de organización provincial o corporativo, como las habían formado la Hermandad de las villas de Cantabria o los reinos de Galicia y Valencia.

Durante el año 1630 hombres de negocios de Alicante, Cartagena y Génova introdujeron algunos barcos en ella y nombraron almirante a Francisco Imperial, vecino de Alicante, quien había dado poder el día 21 de enero de 1630 a su hermano Deodato

89. AHPM, Prot. 5226, f. 11

90. AHPM, Prot. 5226, f. 128v, 17-7-1630. 
Imperial para «hacer y tratar cualquier concierto con Guillermo Garret en razón del consulado y administración de las cosas de la armada y flota de seis galeones que pretende armar con licencia de Su Majestad de guerra y comercio»" ${ }^{91}$.

Años más tarde, antes de 1636, año de su muerte, en la introducción de un libro dedicada a Deodato Imperial y su linaje, se habla de Francisco Imperial como almirante de una flota de seis o siete galeones que hizo mucho daño a los corsarios de Argel en $1635^{92}$.

También sabemos que en 29 de abril de 1636 Vicente Imperial, hermano de Francisco, entró en el puerto de Cartagena con una fragata argelina capturada por é ${ }^{93}$.

La adquisición de barcos se vio favorecida por los embargos realizados por los oficiales de la Proveeduría de Armadas y Fronteras contra los enemigos. En 1627 Juan Bta. Lamberto, cónsul de Francia, compró a Martín de Arazola, Francisco Manzano y doña Bernarda de Bilbao, viuda del secretario Gaspar de Salzedo, una tercera parte del navío embargado San Pedro, del que había sido capitán Felipe Juan Seius, por 2.666 reales $^{94}$, a lo que contribuyó la reanudación de las guerras y la acción del Almirantazgo en lo que se refiere a ventas de barcos, a favor de los flamencos.

\section{LOS CONTRATOS NOTARIALES ALICANTINOS}

En líneas generales los contratos notariales alicantinos eran diferentes a los castellanos, pues en Alicante predominaron las ápocas o recibos sobre las cartas de pago, así como las procuraciones sobre los poderes, a diferencia de Cartagena y Murcia, donde lo hicieron las obligaciones de pago y los poderes, respectivamente. En Cartagena se constata una mayor abundancia de escrituras de portes y de fletamientos, que por contraste fueron muy escasas entre los registros del notario alicantino Martí Moliner.

$\mathrm{Al}$ hacer recuento, se observa una paulatina reducción de las escrituras en que intervinieron mercaderes, proceso que podemos atribuir en parte a que algunos de estos mercaderes pasaron a ser considerados ciudadanos y caballeros (Juan Musiteli, Guillermo Paulin, Esteban Rizo).

Por otra parte, también llama la atención la importancia de la contratación relacionada con Villena, Yecla y otras poblaciones castellanas. De hecho, Yecla era la población, junto con Almansa (pero ésta se relacionó también con Valencia), por cuya aduana pasaba la mayor parte del tráfico de mercancías desembarcadas en Alicante con destino a la meseta castellana.

Un estudio de las actas notariales (actas, contratos y declaraciones) otorgadas por los mercaderes de Alicante entre 1633 y 1643, a partir del catálogo de Alberola, nos permite un conocimiento más detallado de sus actividades, aunque evidentemente limitado, pues no contamos con sus libros de contabilidad o libros de cuenta y razón, ni con otras fuentes fiscales que reflejen sus contribuciones.

91. AHPM, Prot. 5226, 1630, fs. 8-9.

92. P. CAStro y ANAYA, Historia de la perversa vida y horrenda muerte del Anticristo, Murcia, 1635.

93. AHPM, Prot. 5300, f. 255, 8-10-1636

94. AHPM, Prot. 5225, f. 92, 18-8-1627. 
Hay que precisar que en estos protocolos se llama mercaderes a todos los comerciantes, sin que se distinga entre hombres de negocios y mercaderes, diferenciación que sí hemos visto hacer en protocolos alicantinos de 1688-1700. Pero, por contraste, advertimos que en estos años 1633-1643 algunos de los que aparecen consignados al principio como mercaderes, con el paso del tiempo recibieron denominaciones diferentes, como la de ciudadano o caballero (Guillermo Paulin y Esteban Rizo ya en 1635), que hacen referencia a una condición social privilegiada que adquirieron. Este hecho nos ha impelido a incluir entre las obligaciones mercantiles las otorgadas por ciudadanos y caballeros que antes fueron denominados mercaderes, como los ya mencionados y otros (Juan Musiteli, Jusep Paravecín y Gaspar Suqueto), de tal forma que en 1642 las obligaciones otorgadas por caballeros o ciudadanos fueron numerosas (41).

En cuanto a la actuación documental de los mercaderes considerada en su conjunto esta consistía principalmente en el otorgamiento de ápocas (recibos), obligaciones de pagos, poderes y procuras, y mucho menos de cambis, capbreus, cancelaciones, cesiones, disoluciones, lluiciones, promesas, protestos, reconocimientos, revocaciones, restituciones, sustituciones, testamentos y ventas. De un análisis global cabe deducir que la obligación de pago era la más importante, pues aunque la ápoca o recibo era a veces más numerosa tenía un carácter dependiente, es decir, se posponía a otro contrato, al que completaba.

Por otra parte, hemos localizado sólo unos pocos testamentos de mercaderes, alguno de ellos no en el fondo notarial alicantino conservado en el Archivo de los Marqueses del Bosch, sino en el fondo documental Someruelos de la Sección Nobleza del Archivo Histórico Nacional, como es el testamento de Artibaro Bojoni y Ana Quirós, su mujer. Él era mercader y ella, ya viuda, dedicada también al comercio. Sus relaciones con Italia, de donde parece proceder, se constatan en su relación con Filipo Andrioti, pero también las tenía con castellanos y valencianos, como Luis Rincón (acreedor de 200 reales por cuentas pasadas). Algunas de sus hijas casaron con mercaderes de Alicante, como Francisco Moxica, también italiano, y Pedro Vicente Rodríguez ${ }^{95}$.

Los recuentos de tipos de escrituras y procedencias de los compradores ofrecen apreciaciones que nos parecen muy valiosas. Así, en 1633-1637 el mayor número de obligaciones de pagos correspondieron a ventas de ropa, pero en una evolución decreciente $(20,12,9,1,8$ y 9 de 38, 23, 18, 16 y 23$)$. Estas ventas fueron realizadas por mercaderes (Marco Antonio Paravaña), o por sus cónyuges (Ana Quirós, viuda de Artibaro Bojoni), y por tenderos (Nofre Mallol y Francisco Carrua), a diferencia de las ventas de pescado $(5,3,8,12$ y 6$)$ y de algarroba (3), castañas (1), cera (1), cuero (1), ganado (1), lana (1), papel (2), pimienta (2), solimán (1) y tabaco (2), que fueron hechas por mercaderes genoveses e ingleses. La clientela compradora procedió de Alicante $(8,11$, 5 y 3), Alcira (1), Altea (1), Asp (1), Benimagrell (4), Biar (2 y 2), Busot (1, 2, 1 y 0 ), Cartagena (1), Elche (4, 0,0 y 1$)$, Elda (1), Francia (0 y 1$)$, Guadalest ( 0 y 2$)$, Ibi (1), Játiva $(0,0,0$ y 1$)$, Jávea ( 0 y 1$)$, Madrid $(0,0,1$ y 0$)$, Monforte $(0,0,0$ y 1$)$, Mutxamel

95. AHN, Sección Nobleza, fondo Someruelos, caja 5, doc. 9, Testamento de Artibano Bojoni, 9-2-1629. 
$(4,0,2$ y 1$)$, Novelda ( $3,0,0$ y 1$)$, Orihuela ( 0 y 1$)$, Relleu (1), Sant Joan $(2,1,2$ y 0$)$, Tibi $(0,0,0,1)$, Villajoyosa $(0,0,1$ y 3$)$, Villena $(0,0,1$ y 1$)$ y Yecla $(0,2,4$ y 5$)$, es decir, principalmente alicantina.

También en 1642 las obligaciones de pago fueron los instrumentos más utilizados por los mercaderes, junto con las ápocas, en un segundo lugar. Se pueden hacer varias consideraciones de interés sobre su manejo: por ejemplo, fueron muy abundantes para la compra de pescado atlántico, en especial por vecinos de Yecla y otras poblaciones del reino de Murcia (Sax, Villena), pero también por los de otras alicantinas, como Benisa, y valencianas, como Capdet (José Paravecino y Gaspar Suqueto). En años de crisis cerealista, por contraste, predominaron las obligaciones de pago de trigo y cebada, como en 1634 (José Paravecino y Gaspar Suqueto vendieron cantidades notables de cereal a vecinos de Altea y Villajoyosa) y en 1642-1643 con mucha diferencia sobre las demás, pero en este último caso los deudores fueron vecinos de las villas y lugares cercanos a Alicante, como Mutxamel (43), Asp (33), Sant Joan (29), Busot (11), Benimagrell (9), Novelda (3) y Monfort (2), y del propio Alicante (30), que compraron a mercaderes (Tomás Sempere y Pablo Jerónimo Ribanegra y Juan Bautista Patucio, compañía de comercio). Aunque en mucha menor cantidad vendieron también cereal algunos caballeros (Francesc Pasqual de Mingot, Pablo Salafranca, Julio Escorcia) y ciudadanos (Francesc Romeu, de Valencia), de los cuales algunos afrontaron viajes marítimos para comprar el trigo en Orán (Francesc Pasqual de Mingot, Mauricio Carrera), y otros quizá la vendieron de su cosecha (Pablo Salafranca, sólo cebada). Se advierte en este último grupo, el de caballeros, su origen extranjero, ya francés (Salafranca) o genovés (Escorcia), personas cuyos padres ya se habían ennoblecido en la ciudad, sobre todo por la vía del matrimonio.

Fue utilizada asimismo la obligación para el contrato del transporte de papel desde Alicante a Madrid y Toledo, realizado por transportistas de Almansa, Junquillos y Tembleque (poblaciones castellanas), por comisión de Juan Agustín Ansaldo (1642), para Nicolás Barberini, también genovés, o de espadas, enviadas por José Paravecino y Gaspar Suqueto a Alejandro Carminati. Quedaron entonces en un lugar muy marginal las ventas de tejidos (Ana Quirós, viuda de Artibano Bojoni) y de cera mediante obligación (Francesc Romeu), o el encargo de dispensas matrimoniales en Roma.

En algunos casos estos contratos muestran una actividad ocasional, la de mercaderes que no debieron permanecer mucho tiempo en Alicante. Así, Gaspar Sánchez Monterdi sólo aparece en 1637. Se dedicó a vender ropa a otros mercaderes, de Cartagena (Ginés de Iniesta), Murcia (Agustín Ros) y Saboya (Joan Viat), a este último al fiado para que la vendiera por los pueblos de la comarca. De forma parecida, Jacinto Giner consta sólo en el mismo año, vendiendo sardina irlandesa a vecinos de Altea y Yecla.

\section{LA CONTRATACIÓN DE FLETES, LETRAS DE CAMBIO Y ASIENTOS DE LA PROVEEDURÍA DE ARMADAS Y FRONTERAS DE CARTAGENA}

Los comerciantes genoveses de Alicante y Cartagena hacían cargar sus barcos en uno y otro puerto, ya disponiendo embarcar la mercancía enteramente en uno de ellos, ya sólo previendo completarla en el otro. 
Así, Juan Bta. Lamberto apoderó a Francisco Baldovinos, milanés, capitán del navío San Juan, propiedad de Lamberto, para que fuera con él a Alicante y buscara entre hombres de negocios mercancías para cargar y llevar a Génova o Liorna, concertando su fletamiento ${ }^{96}$.

Esta adquisición pudo asociar a comerciantes de ambas ciudades, como sucedió también con la formación de la Flota del Mediterráneo, y de ello dan muestra la venta de la tartana Sta. María Buenaventura ( 3 áncoras, 2 tiendas y un cabo) de Joan Estévez, catalán de Palamós, a Vicente Pascual, vecino de Alicante, por 960 reales $^{97}$, y el nombramiento de capitán por Pelegro Sibori, mercader genovés de Cartagena, y Bartolomé Isola, de Alicante, en razón de su propiedad de la tartana Santa María Buenaventura, a Juan López, vecino de Alicante, dándole facultad para fletarla y obligándole a rendir cuenta de fletes y cargazones a cada uno de ellos en su respectiva ciudad ${ }^{98}$.

Pero también se contrataban fletamientos en Cartagena para cargar en Alicante. Por ejemplo, el realizado por Carlos Carminati, vecino de Cartagena, en nombre de Francisco Moxica y Juan Musiteli, vecinos de Alicante, con Giles Fetiplas, inglés residente en Cartagena, sobre el navío La Asiguranza del capitán Ricardo Helman, vecino de Londres, para cargar en Alicante 550 sacas de lana lavada, de a 14 arrobas cada arroba, con destino a Venecia, de flete a 85 reales de plata doble por saca de 14 arrobas $^{99}$.

Además de la administración conjunta de mercancías y de fletes entre mercaderes de Alicante y Cartagena, la colaboración se extendió a las letras de cambio. Bartolomé Baldasano, mercader genovés de Cartagena, reconoció el pago de 3200 reales de plata a Juana Digueri, viuda de Deodato Imperial, en nombre de Juan Agustín Ansaldo, vecino de Alicante, todos naturales de Génova, como cesionario de Andrés Andresson de Noruega, capitán del navío Santa María de Noruega, por poder dado en Alicante en 144-1636, y en virtud de una letra de cambio firmada por Richarte Reguill y Guillermo Beart, ingleses de Málaga, de 14-2-1636 ${ }^{100}$.

Cartagena se singularizaba de Alicante en que era sede de la Proveeduría de Armadas y Fronteras, desde la que se abastecía a las escuadras de galeras (España, Estrecho, Nápoles y Sicilia) y a los presidios de Berbería (Orán y Mazalquivir). Esta fue una actividad muy vinculada a las guerras que se generalizaron en esta época.

Comerciantes de Alicante invirtieron conjuntamente con los de Cartagena en el tráfico comercial marítimo y, además de ello, también separadamente en negocios muy distintos, incluso asientos para las almadrabas pesqueras del reino de Murcia, el abastecimiento de pescado o la provisión de pólvora a la artillería en Cartagena.

La pólvora era suministrada generalmente por asentistas, como algún genovés de Alicante; y aunque la fabricación era controlada por los oficiales reales de la artillería,

96. AHPM, Prot. 5225, f. 104r, 1-X-1626.

97. AHPM, Prot. 6224, 17-6-1620.

98. AHPM, Prot. 5225, fs. $129 \mathrm{v}-130 \mathrm{v}, 3-10-1627$

99. AHPM, Prot. 5300, fs. 423-424, 5-12-1636.

100. AHPM, Prot. 5300, f. 312, 25-9-1636. 
el suministro de pólvora y salitre se hacía por asiento para el distrito de los reinos de Granada y Murcia. Para la fabricación de pólvora se recurrió a comerciantes genoveses de Alicante, como Juan Bta. Semino (1624), y más tarde al portugués Antonio Grafior (1636), que compraban salitre en Alhama de Murcia y Totana y recurrían a molinos de pólvora de particulares, como el de Juan Bautista en Caravaca (1636).

La provisión de pólvora la concertó en 1624 Juan Bta. Semino, mercader de Alicante, con un poder a Bartolomé Baldasano, mercader genovés de Cartagena, y se llevó a efecto mediante un asiento que Baldasano contrató con Juan Escarramad, teniente del capitán general de la artillería en Cartagena, por el que Semino se obligó a entregar 360 quintales en 8 plazos mensuales de 60 quintales mensuales, a 146 reales de plata doble el quintal, adelantándole 11000 de ellos ${ }^{10 !}$.

Por contraste, la guerra encareció la navegación comercial, pues ni la presencia de las escuadras de galeras de Génova, Nápoles y Sicilia, ni la administración militar regnícola (los oficiales del adelantamiento mayor murciano y de la proveeduría de armadas y fronteras de Cartagena) proporcionaban una seguridad satisfactoria para el transporte marítimo.

Se trataba de un espacio con relaciones profesionales y económicas estrechas, entabladas entre mercaderes genoveses y franceses de Alicante, Cartagena y Génova, en una coyuntura económica que se complicó a partir de 1621 y 1635 con la crisis industrial en el norte de Italia y la política de reputación del conde duque de Olivares, que llevó a la entrada en numerosos conflictos, como los mencionados, en el contexto de la crisis general de la guerra de los Treinta Años (1618-1648).

101. AHPM, Prot. 5510, fs. 141-143, 26-4-1624. 